\title{
ANALISIS FAKTOR-FAKTOR YANG MEMPENGARUHI TERHADAP TERJADINYA PENYAKIT JANTUNG KORONER DI POLI JANTUNG RSUD PIRNGADI MEDAN TAHUN 2017
}

\section{Analysis of Influencing Factors of Coronary Heart Disease in Heart Patients in Pirngadi Hospital Medan Year 2017}

\author{
Siti Aisyah Syafrul ${ }^{1}$, Daniel Ginting ${ }^{2}$, Janno Sinaga ${ }^{2}$ \\ ${ }^{1}$ Program Studi Pasca Sarjana Kesehatan Masyarakat Universitas Sari Mutiara Indonesia \\ Email: iecha.syafrul@yahoo.com \\ ${ }^{2}$ Dosen Program Studi Pasca Sarjana Kesehatan Masyarakat \\ Universitas Sari Mutiara Indonesia \\ Email: daniginting_simpangsuka@yahoo.co.id
}

\begin{abstract}
Abstrak
Berbagai faktor risiko ditengarai mendorong terjadinya PJK, sebagian dapat dimodifikasi tetapi sebagian lagi tidak.Tujuan penelitian ini adalah untu menganalisis faktor-faktor yang mempengaruhi terhadap terjadinya penyakit jantung koroner di Poli Jantung RSUD Pirngadi Medan Tahun 2017. Populasi kasus dalam penelitian ini adalah semua penderita jantung Koroner yang datang berobat ke di RSUD Pirngadi Medan 2017 pada tahun 2017 berjumlah 491 orang. Dari hasil perhitungan ini maka peneliti menetapkan jumlah sampel sebanyak 83 orang. Hasil penelitian menunjukkan bahwa ada Berdasarkan hasil yang diperoleh bahwa jenis kelamin berpengaruh terhadap kejadian jantung koroner dengan nilai $\mathrm{p}=0,023$, usia berpengaruh terhadap kejadian jantung coroner, Kebiasaan Merokok berpengaruh terhadap kejadian jantung coroner. Hipertensi terhadap kejadian jantung coroner. Diabetes (DM) terhadap kejadian jantung coroner. Obesitas berpengaruh terhadap kejadian jantung koroner. Aktifitas Fisik berpengaruh terhadap kejadian jantung koroner. Disarankan upaya pencegahan penyakit tidak menular terutama penyakit jantung koroner pada perempuan lebih bermanfaat dilakukan dari usia remaja, sehingga faktor risiko bisa dikendalikan sejak dini, khususnya mengendalikan obesitas dan pola makan yang sehat melalui aktivitas fisik dan pola makan sehat; tinggi serat, rendah lemak, rendah garam dan gula.

Kata Kunci : Faktor-Faktor Yang Mempengaruhi Terhadap Terjadinya Penyakit Jantung Koroner
\end{abstract}

\begin{abstract}
Various risk factors are suspected to encourage the occurrence of CHD, some may be modified but some are not. The purpose of this study is to analyze the factors that affect the occurrence of Coronary Heart Disease In Cardiovascular Poly Pirngadi Medan Year 2017. Case population in this study is all heart patients Coroner who came to treatment at Pirngadi Hospital 2017 in 2017 amounted to 491 people. From the results of this calculation then the researchers set the number of samples as many as 83 people. The results showed that there was Based on the results obtained that the sex effect on coronary heart events with $\mathrm{p}$ value $=0.023$, age affects coronary heart events, Smoking Habit affect coronary heart events. Hypertension to coronary heart events. Diabetes (DM) against coronary heart events. Obesity has an effect on coronary heart event. Physical activity has an effect on coronary heart event. Suggested efforts to prevent non-communicable diseases, especially coronary heart disease in women more useful done from adolescence, so that risk factors can be controlled early, especially controlling obesity and healthy diet through physical activity and healthy diet; high fiber, low fat, low salt and sugar.
\end{abstract}

Keywords: Factors Affecting Against Coronary Heart Disease 


\section{PENDAHULUAN}

Organisasi Kesehatan Sedunia (WHO) dan Organisasi Federasi Jantung Sedunia (World Heart Federation) memprediksi penyakit jantung akan menjadi penyebab utama kematian di negara-negara Asia pada tahun 2010.Sedikitnya 78\% kematian global akibat penyakit jantung terjadi pada kalangan masyarakat miskin dan menengah. Berdasarkan kondisi itu, dalam keadaan ekonomi terpuruk maka upaya pencegahan merupakan hal terpenting untuk menurunkan penyakit kardiovaskuler pada 2010 (Abidin, 2014).

Penyakit jantung koroner merupakan penyakit yang banyak diderita oleh masyarakat.Penyakit ini menyerang pembuluh darah yang mengalirkan darah ke jantung (arteri koroner) sehingga terjadi penyempitan pada arteri koroner. Fenomena yang terjadi sejak abad ke-20, penyakit jantung dan pembuluh darah telah menggantikan peran penyakit tuberculosis paru sebagai penyakit epidemic di Negara -negara maju, terutama pada laki-laki (Supriyono, 2008). Berdasarkan data WHO (2011) bahwa penyakit jantung merupakan penyebab kematian nomor satu di dunia dan sedikitnya 17,5 juta atau setara dengan $30 \%$ kematian di seluruh dunia disebabkan oleh penyakit jantung (Ruanita, 2013). Tahun 2030 diperkirakan sekitar 23,6 juta penduduk dunia akan meninggal karena penyakit ini. Peningkatan jumlah kematian terbesar akan terjadi di wilayah Asia Tenggara. American Heart Association juga menyatakan bahwa Penyakit Jantung Koroner $(P J K)$ telah menyebabkan 425 kematian pada tahun 2006 (Ruanita, 2013).

Indonesia saat ini menghadapi masalah kesehatan yang kompleks dan beragam. Tentu saja mulai dari infeksi klasik dan modern, penyakit degeneratif serta penyakit psikososial yang menjadikan Indonesia saat ini yang menghadapi " threeple burden diseases". Berdasarkan hasil Survei Kesehatan Rumah Tangga Nasional (SKRTN), dalam 10 tahun terakhir angka tersebut cenderung mengalami peningkatan. Pada tahun 1991, angka kematian akibat Penyakit Jantung Koroner $(P J K)$ adalah $16 \%$. kemudian di tahun 2001 angka tersebut melonjak menjadi 26,4\%. Angka kematian akibat Penyakit Jantung Koroner (PJK) diperkirakan mencapai 53,5 per 100.000 penduduk di negara kita. Data SKRT tahin
2002 menunjukan bahwa kematian akibat penyakit jantung koroner dan pembuluh darah (usia diatas 15 tahun) sebesar 6,0\% dan 8,4\% pada tahun 2005. Data Depkes kematian terbanayak di seluruh rumah sakit di Indonesia dengan jumalah kematian 2.557 jiwa. Berdasarkan Riset kesehatan dasar tahun 2007, angka kematian pada kelompok usia 45 - 54 tahun di daerah perkotaan akibat penyakit jantung iskemik 8,7\% (Elza, 2013).

Tingginya prevalensi penyakit jantung (khususnya penyakit jantung koroner) diakibatkan oleh sejumlah faktor yang berhubungan dengan pola hidup danperilaku masyarakat yang cenderung mengalami pergeseran. Faktor yang dikenal sebagai faktor risiko yang meningkatkan kerentanan terhadap terjadinya aterosklerosis coroner (penyebab Penyakit Jantung Koroner) pada individu tertentu, yaitu 1). Faktor risiko yang tidak dapat diubah (usia, jenis kelamin, riwayat PJK dalam keluarga); 2). Faktor risiko yang dapat diubah (hiperlipidemia, hdl-c rendah,hipertensi, merokok, DM, obesitas, ketidakaktifan fisik, hiperhormosisteinemia) (Sudayasa, 2015). Maani (2012) telah menemukan hubungan antara hipertensi, DM dan obesitas dengan kejadian PJK di Rumah Sakit Umum Bahteramas Provinsi Sulawesi Tenggara tahun 2012.

Salah satu olahraga yang dapat dilakukan adalah senam. Salah satu senam adalah senam aerobik, Senam aerobik merupakan senam kelenturan yang ditingkatkan dengan memacu jantung dan paru-paru, dimana gerak kaki sebagai penunja ng selalu ada, baik dalam gerakan senamnya maupun dalam bentuk jalan atau lari ditempat, yang bertujuan memacu jantung.

Senam jantung sehat adalah olahraga yang disusun dengan selalu mengutamakan kemampuan jantung, gerakan otot besar dan kelenturan sendi, agar dapat memasukkan oksigen sebanyak mungkin ke dalam tubuh.Senam jantung sehat bertujuan merawat jantung dan pembuluh darah.Pembuluh darah yang sehat, membuat kerja jantung menjadi optimal, karena kedua organ tersebut bekerja saling berhubungan (Sarvasty, 2012).Senam jantung sehat menjadi salah satu olahraga atau aktivatas fisik yang dapat bisa menurunkan resiko terja dinya penyakit kardiovaskular (Subekti,2015). 
Berdasarkan data survei awal di RSUD Dr. Pirngadi Medan dari bulan Januari - Mei 2017 pasien penyakit jantung koroner berjumlah 491 orang. Dengan demikian dari jumlah tersebut diperkirakan rata-rata pasien penyakit jantung Koroner 17 orang per harinya.Dari hasil studi pendahuluan yang dilakukan peneliti juga telah mewawancarai 8 orang pasien laki -laki yang mempunyai riwayat merokok sebelum didiagnosa Penyakit Jantung Koroner (PJK), duaorang mengatakan telah berhenti merokok, tiga orang mengatakan belum bisa berhenti total. Data lain yang didapat, limadari delapan pasien mengungkapkan tidak melakukan olah raga, tiga orang pasien mengaku berolahraga teratur $1 \mathrm{x}$ setiap minggunya. Dua orang pasien mengatakan bahwa mereka sebisa mungkin mengatur pola makan dengan menghindari konsumsi makanan yang tidak dianjurkan, sisanya enam orang pasien mengaku masih mengkonsumsi makanan yang tidak dianjurkan.

\section{METODE PENELITIAN}

Penelitian ini menggunakan penelitian cross-sectional yaitu observasi atau pengukuran variabel penelitian dilakukan pada satu waktu saja untuk mengetahui Analisis Faktor-Faktor yang Mempengaruhi terhadap Terjadinya Penyakit Jantung Koroner di Poli Jantung RSUD Pirngadi Medan Tahun 2017.

Penelitian ini dilaksanakan di RSUD Pirngadi Medan 2017. Penelitian ini dilaksanakan mulai dari bulan Juli sampai dengan Agustus 2017. Populasi dalam penelitian ini adalah semua penderita jantung Koroner yang datang berobat ke di RSUD Pirngadi Medan 2017 pada tahun 2017. Berdasarkan data survei awal di RSUD Dr. Pirngadi Medan dari bulan Januari - Mei 2017 pasien penyakit jantung koroner berjumlah 491 orang. Dengan demikian jumlah populasi adalah 491 orang.

Dalam penelian ini sampel adalah semua penderita jantung Koroner yang datang berobat di RSUD Pirngadi Medan mulai Januari s/d Desember 2016. Penentuan jumlah sampel ditentukan dengan menggunakan rumus Slovin. Dari hasil perhitungan ini maka peneliti menetapkan jumlah sampel sebanyak 83 orang.

Analisis univariat yang merupakan analisis deskriptif untuk melihat distribusi frekuensi pada tiap variabel (variabel bebas dan terikat). Analisis bivariat untuk melihat hubungan antara variabel bebas dengan variabel terikat secara sendiri-sendiri dengan menggunakan chi-square pada taraf kepercayaan $95 \%(\mathrm{p}<0,05)$.

\section{HASIL PENELITIAN}

\section{Analisa Univariat}

Deskripsi responden dalam penelitian ini menggambarkan karakteristik responden menurut usia, jenis kelamin, Merokok, Hipertensi, Diabetes, Obesitas, aktifitas fisik dan kejadian Penyakit Jantung.

Tabel 4.1Karakteristik Responden di Poli Jantung RSUD Pirngadi MedanTahun 2017

\begin{tabular}{|c|c|c|}
\hline Jenis Kelamin & Frekuensi (f) & Persentase $(\%)$ \\
\hline Laki-laki & 48 & 57.8 \\
\hline Perempuan & 35 & 42.2 \\
\hline Total & 83 & 100.0 \\
\hline Usia (tahun) & Frekuensi (f) & Persentase $(\%)$ \\
\hline$>35$ Tahun & 53 & 63.9 \\
\hline$\leq 35$ tahun & 30 & 36.1 \\
\hline Total & 83 & 100.0 \\
\hline $\begin{array}{c}\text { Kebiasaan } \\
\text { merokok }\end{array}$ & $\begin{array}{l}\text { Frekuensi } \\
\text { (f) }\end{array}$ & $\begin{array}{c}\text { Persentase } \\
(\%)\end{array}$ \\
\hline Merokok & 59 & 71.1 \\
\hline Tidak Merokok & 24 & 28.9 \\
\hline Total & 83 & 100.0 \\
\hline Hipertensi & $\begin{array}{l}\text { Frekuensi } \\
\text { (f) }\end{array}$ & $\begin{array}{c}\text { Persentase } \\
(\%)\end{array}$ \\
\hline Hipertensi & 67 & 80.7 \\
\hline Tidak Hipertensi & 16 & 19.3 \\
\hline Total & 83 & 100.0 \\
\hline Diabetes & $\begin{array}{l}\text { Frekuensi } \\
\text { (f) }\end{array}$ & $\begin{array}{c}\text { Persentase } \\
(\%)\end{array}$ \\
\hline DM & 62 & 74.7 \\
\hline Tidak DM & 21 & 25.3 \\
\hline Total & 83 & 100.0 \\
\hline Obesitas & $\begin{array}{c}\text { Frekuensi } \\
\text { (f) }\end{array}$ & $\begin{array}{c}\text { Persentase } \\
(\%)\end{array}$ \\
\hline 67 & 80.7 & 67 \\
\hline 16 & 19.3 & 16 \\
\hline 83 & 100.0 & 83 \\
\hline Aktifitas Fisik & $\begin{array}{l}\text { Frekuensi } \\
\text { (f) }\end{array}$ & $\begin{array}{c}\text { Persentase } \\
(\%)\end{array}$ \\
\hline$>3 x /$ minggu & 15 & 18.1 \\
\hline$\leq 3 \mathrm{x} /$ minggu & 68 & 81.9 \\
\hline Total & 83 & 100.0 \\
\hline $\begin{array}{l}\text { Kejadian } \\
\text { Penyakit } \\
\text { Jantung }\end{array}$ & $\begin{array}{l}\text { Frekuensi } \\
\text { (f) }\end{array}$ & $\begin{array}{c}\text { Persentase } \\
(\%)\end{array}$ \\
\hline Kejadian & 62 & 74.7 \\
\hline Tidak Kejadian & 21 & 25.3 \\
\hline Total & 83 & 100.0 \\
\hline
\end{tabular}

Sumber : Data diolah (2017) 
Dari Tabel 4.1. di atas dapat dijelaskan bahwa karakteristik responden untuk Jenis Kelamin mayoritas Laki-laki sebanyak 48 orang $(57.8 \%)$,mayoritas responden kelompok umur > 35 Tahunsebanyak 53 orang (63.9\%), mayoritas responden adalah perokok yaitu 59 orang $(71.1 \%)$, mayoritas responden memiliki hipertensi yaitu 67 orang $(80.7 \%)$, mayoritas responden memiliki penyakit DM yaitu 62 orang $(74,7 \%)$, Mayoritas responden memiliki aktifitas fisik $\leq 3 \mathrm{x} /$ minggu yaitu 68 orang $(81,9 \%)$, Mayoritas responden mengalami kejadian penyakit jantung yaitu 62 orang $(74,7 \%)$

\section{Analisa Bivariat}

Analisis bivariat adalah analisis yang dilakukan untuk mengetahui keterkaitan dua variable. Dalam pembahasan ini dilihat hubungan antara karakteristik individu yaitu usia, jenis kelamin, Merokok, Hipertensi,Diabetes, Obesitas, aktifitas fisik dan kejadian Penyakit Jantung.

\section{Hubungan Karakteristik Jenis kelamin dengan kejadian penyakit Jantung di Poli Jantung RSUD Pirngadi Medan Tahun 2017}

Tabel 4.2. Jenis Kelamin Dengan kejadian Jantung

\begin{tabular}{|c|c|c|c|c|c|c|}
\hline \multirow{3}{*}{ Jenis kelamin } & \multicolumn{4}{|c|}{ kejadian Jantung } & \multirow{2}{*}{\multicolumn{2}{|c|}{ Total }} \\
\hline & \multicolumn{2}{|c|}{ Kejadian } & \multicolumn{2}{|c|}{ Tidak } & & \\
\hline & $\mathrm{f}$ & $\%$ & $f$ & $\%$ & f & $\%$ \\
\hline Laki-laki & 39 & 81.2 & 9 & 18,8 & 48 & 100 \\
\hline Perempuan & 25 & 71,4 & 10 & 28,6 & 35 & 100 \\
\hline Total & 64 & 77,1 & 19 & 22,9 & 83 & 100 \\
\hline
\end{tabular}

Dari 48 orang responden yang memiliki umur $\leq 25$ tahun diperoleh 39 responden $(81,2 \%)$ yang mengalami kejadian Jantung dan 9 orang $(18,8 \%)$ yang tidak mengalami kejadian jantung. Dari 35 responden yang memiliki umur $>25$ tahun diperoleh 25 orang $(71,4 \%)$ yang memiliki kejadian Jantung dan 10 orang responden $(28,6 \%)$ yang tidak mengalami kejadian jantung.Hasil uji Chi-Square menunjukkan bahwa nilai $\mathrm{p}=0.023<0,05$ yang artinya ada hubungan yang signifikan antara Jenis kelamin dengan kejadian Jantung.

\section{Hubungan Karakteristik Usia dengan kejadian penyakit jantung di Poli Jantung RSUD Pirngadi Medan Tahun 2017}

Tabel 4.3. Usia Dengan Kejadian Jantung

\begin{tabular}{|c|c|c|c|c|c|}
\hline \multirow[b]{2}{*}{ Usia } & \multicolumn{4}{|c|}{ kejadian jantung } & \multirow[b]{2}{*}{ Total } \\
\hline & & jadian & & Tidak & \\
\hline \multirow{3}{*}{$\begin{array}{l}\leq 35 \text { tahun } \\
>35 \text { tahun }\end{array}$} & $\mathrm{f}$ & $\%$ & $f$ & $\%$ & f $\%$ \\
\hline & 5 & 100 & 0 & 0 & 5100 \\
\hline & 59 & 75,64 & $\begin{array}{l}1 \\
9\end{array}$ & 24,36 & $\begin{array}{ll}7 & 100 \\
8 & 100\end{array}$ \\
\hline Total & 64 & 68.8 & $\begin{array}{l}1 \\
9\end{array}$ & 31,2 & $\begin{array}{ll}9 & 100 \\
3 & 100\end{array}$ \\
\hline
\end{tabular}

Dari 5 orang responden yang memiliki usia $\leq 35$ tahundiperoleh 5 responden (100\%) yang mengalami kejadian Jantung. Dari 78 responden yang memiliki umur > 35 tahundiperoleh 59 orang $(75,64 \%)$ yang memiliki kejadian Jantung dan 19 orang responden $(24,36 \%)$ yang tidak mengalami kejadian jantung.

Dari 11 responden yang memiliki umur Masa dewasa Akhir =36- 45 tahun diperoleh 8 orang $(72,7 \%)$ yang memiliki kejadian Jantung dan 3 orang responden $(27,3 \%)$ yang tidak mengalami kejadian jantung. Dari 31 responden yang memiliki umur Masa Lansia Awal = 46- 55 tahun diperoleh 19 orang $(61,3 \%)$ yang memiliki kejadian Jantung dan 12 orang responden $(38,7 \%)$ yang tidak mengalami kejadian jantung. Dari 31 responden yang memiliki umur Masa Lansia Akhir = $56-65$ tahun diperoleh 15 orang $(93,7 \%)$ yang memiliki kejadian Jantung dan 1 orang responden $(6,3 \%)$ yang tidak mengalami kejadian jantung.

Hasil uji Chi-Square menunjukkan bahwa nilai $\mathrm{p}=0,010<0,05$ yang artinya ada hubungan yang signifikan antara Usiadengan kejadian Jantung.

\section{Hubungan Karakteristik Kebiasaan Merokok dengan kejadian penyakit jantung di Poli Jantung RSUD Pirngadi Medan Tahun 2017}

Tabel 4.4 Kebiasaan Merokok Dengan kejadian jantung

\begin{tabular}{|c|c|c|c|}
\hline \multirow{3}{*}{$\begin{array}{l}\text { Kebiasaan } \\
\text { Merokok }\end{array}$} & \multicolumn{2}{|c|}{ kejadian jantung } & \multirow[b]{2}{*}{ Total } \\
\hline & Kejadian & Tidak & \\
\hline & f $\%$ & $\%$ & f $\quad \%$ \\
\hline Merokok & 46 & $13 \quad 22$ & 100 \\
\hline
\end{tabular}




\begin{tabular}{ccccccc}
$\begin{array}{l}\text { Tidak } \\
\text { Merokok }\end{array}$ & 18 & 75 & 6 & 25 & 24 & 100 \\
\hline Total & 64 & 77,1 & 19 & $\begin{array}{c}22, \\
9\end{array}$ & 83 & 100 \\
\hline
\end{tabular}

Dari 59 orang responden yang memiliki kebiasaan merokok diperoleh 46 responden (80\%) mengalami kejadian Jantung dan 22 orang (59\%) yang tidak mengalami kejadian jantung. Dari 24 responden yang memiliki kebiasaan Tidak Merokok diperoleh 18 orang $(75 \%)$ yang memiliki kejadian Jantung dan 6 orang responden (25\%) yang tidak mengalami kejadian jantung. Hasil uji Chi-Square menunjukkan bahwa nilai $\mathrm{p}=0,001<0,05$ yang artinya ada hubungan yang signifikan antara Merokok dengan kejadian Jantung.

Hubungan Hipertensi dengan Kejadian Penyakit jantung di Poli Jantung RSUD Pirngadi Medan Tahun 2017
Kejadian Penyakit Jantung

\begin{tabular}{|c|c|c|c|c|c|c|}
\hline \multirow{3}{*}{$\begin{array}{l}\text { Diabetes } \\
(\mathrm{DM})\end{array}$} & & & & & & \\
\hline & \multicolumn{2}{|c|}{ Kejadian } & \multicolumn{2}{|c|}{ Tidak } & \multicolumn{2}{|c|}{ Total } \\
\hline & $\mathrm{F}$ & $\%$ & $\mathrm{f}$ & $\%$ & $\mathrm{f}$ & $\%$ \\
\hline DM & 60 & 96,8 & 2 & 3,2 & 62 & 100 \\
\hline Tidak DM & 4 & 19,1 & 17 & 80,9 & 21 & 100 \\
\hline Total & 64 & 77,1 & 19 & 22,9 & 83 & 100 \\
\hline
\end{tabular}

Dari 62 orang responden yang memiliki Diabetes (DM) diperoleh 60 responden $(96,8 \%)$ mengalami kejadian Jantung dan 2 orang $(3,2 \%)$ yang tidak mengalami kejadian jantung. Dari 21 responden yang tidak memiliki DM diperoleh 4 orang $(9,1 \%)$ yang memiliki kejadian Jantung dan 17 orang responden $(80,9 \%)$ yang tidak mengalami kejadian jantung. Hasil uji Chi-Square menunjukkan bahwa nilai $\mathrm{p}=0,000<0,05$ yang artinya ada hubungan yang signifikan antara Diabetes dengan kejadian Jantung.

\section{Analisa Multivariat}

Tabel 4.16 Hasil Analisis yang Memenuhi Kejadian Penyakit Jantunģ Asumsi Multivariat (Kandidat)

Tabel 4.5 Hipertensi ।

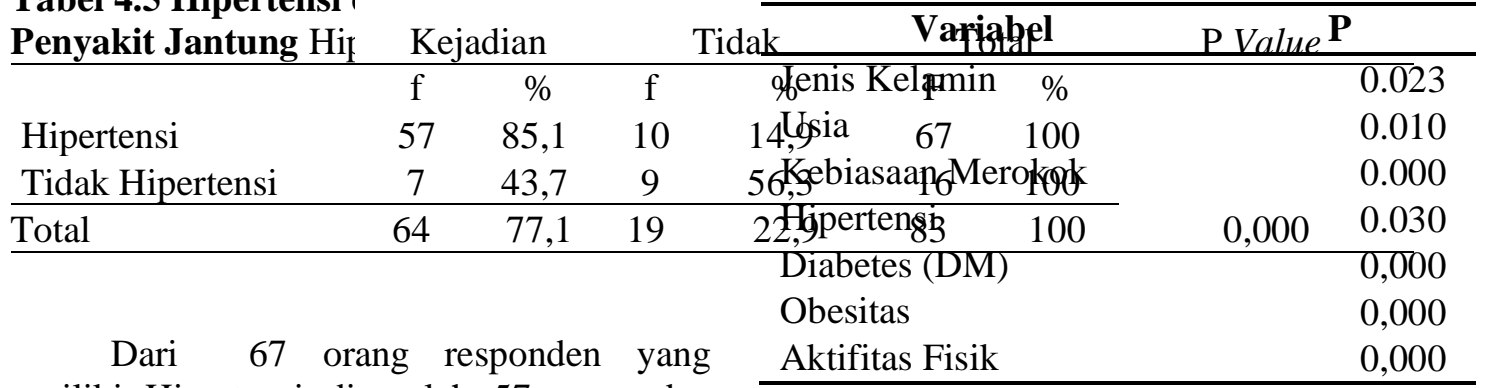

memiliki Hipertensi diperoleh 57 responden $(85,1 \%)$ mengalami kejadian Jantung dan 10 orang $(14,9 \%)$ yang tidak mengalami kejadian jantung. Dari 16 responden yang tidak memiliki hipertensi diperoleh 7 orang $(43,7 \%)$ yang memiliki kejadian Jantung dan 9 orang responden $(22,9 \%)$ yang tidak mengalami kejadian jantung.Hasil uji Chi-Square menunjukkan bahwa nilai $\mathrm{p}=0,000<0,05$ yang artinya ada hubungan yang signifikan antara Hipertensi dengan kejadian Jantung.

Hubungan Diabetes dengan Kejadian Penyakit Jantung di Poli Jantung RSUD Pirngadi Medan Tahun 2017

Tabel 4.6 Diabetes dengan Kejadian Penyakit Jantung
Keterangan :* variabel yang memenuhi syarat

Variabel yang terpilih dalam model akhir regresi logistik ganda dapat dilihat pada Tabel 4.17 berikut :

\section{Tabel 4.17 Hasil Akhir Uji Regresi}

Logistik Berganda

\begin{tabular}{crrr} 
Variabel & B & Sig. & Exp (B) \\
\hline Step 1 $^{\text {a }}$ Jenis Kelamin & .359 & 0.02 & 1.431 \\
Usia & & 0.01 & \\
& 17.041 & 0 & .000 \\
Kebiasaan & & 0.00 & 3.370 \\
Merokok & 17.256 & 0 & \\
Hipertensi & & 0.03 & 1.277 \\
Diabetes (DM) & 2.675 & 0,00 & \\
Obesitas & & 0 & .069 \\
& 37.697 & 0,00 & 2.100 \\
& & 0 &
\end{tabular}


Aktifitas Fisik

2.920

0,00

0

Constant

18.420

.998

Berdasarkan hasil yang diperoleh bahwa jenis kelamin berpengaruh terhadap kejadian jantung koroner dengan nilai $\mathrm{p}=0,023$. jenis kelamin memiliki nilai $\operatorname{Exp}(\mathrm{B})=1,431$ artinya pasien yang memiliki jenis kelamin laki-laki memiliki peluang mengalami penyakit jantung koroner sebesar 1,4 kali lebih besar dibanding dengan responden lainnya

Berdasarkan hasil yang diperoleh bahwa usia berpengaruh terhadap kejadian jantung koroner dengan nilai $\mathrm{p}=0,010$. Kebiasaan merokok memiliki nilai $\operatorname{Exp}(\mathrm{B})=5.410$ artinya pasien yang memiliki $\geq 35$ tahun memiliki peluang mengalami Poli Jantung sebesar 5 kali lebih besar dibanding dengan responden lainnya.

Berdasarkan hasil yang diperoleh bahwa kebiasaan merokok berpengaruh terhadap kejadian jantung koroner dengan nilai $\mathrm{p}=0,005$. Kebiasaan merokok memiliki nilai $\operatorname{Exp}(\mathrm{B})=$ 0,063 artinya pekerja yang memiliki kebiasaan merokok memiliki akan menyebabkan Poli Jantung sebesar 1 kali lebih besar dibanding dengan pasien lainnya.

Ada pengaruh Hipertensi terhadap kejadian jantung koroner dengan nilai $\mathrm{p}=0,000$. Tindakan memiliki nilai Exp $(\mathrm{B})=12.565$. Artinya pasien yang memiliki hipertensi memiliki peluang mengalami Kejadian Penyakit Jantungsebesar 12 kali lebih besar dibanding dengan dengan pasien lainnya.

Ada pengaruh Diabetes (DM) terhadap kejadian jantung koroner dengan nilai $\mathrm{p}=0,030$. Tindakan memiliki nilai $\operatorname{Exp}(\mathrm{B})=1.277$. Artinya pasien yang memiliki Diabetes (DM)memiliki peluang mengalami Kejadian Penyakit Jantung sebesar 1,2 kali lebih besar dibanding dengan dengan pasien lainnya.

Ada pengaruh Obesitas terhadap kejadian jantung koroner dengan nilai $p=0,030$. Tindakan memiliki nilai $\operatorname{Exp}(\mathrm{B})=2.100$. Artinya pasien yang memiliki Obesitas memiliki peluang mengalami Kejadian Penyakit Jantung sebesar 2 kali lebih besar dibanding dengan dengan pasien lainnya.

Ada pengaruh Aktifitas Fisik terhadap kejadian jantung koroner dengan nilai $\mathrm{p}=0,000$. Tindakan memiliki nilai Exp $(\mathrm{B})=18.544$. Artinya pasien yangmemiliki Aktifitas Fisik memiliki peluang mengalami Kejadian
Penyakit Jantung sebesar 18 kali lebih besar dibanding dengan dengan pasien lainnya.

\section{PEMBAHASAN}

Hubungan Karakteristik Jenis kelamin dengan kejadian penyakit jantung

Hasil uji Chi-Square menunjukkan bahwa nilai $\mathrm{p}=0.023<0,05$ yang artinya ada hubungan yang signifikan antara Jenis kelamindengan kejadian Jantung

Jenis kelamin seseorang akan berpengaruh pada kejadian PJK, baik dari efek proteksi aktivitas fisik terhadap PJK maupun faktor risiko PJK lainnya. Perbedaan pengaruh aktivitas fisik terhadap kejadian PJK dipengaruhi kegiatan aktivitas fisik yang dilakukan pada laki -laki dan perempu an. Penelitian oleh Mora (2012), menunjukan bahwa penurunan risiko PJK dengan beraktivitas fisik pada perempuan dan laki laki sebesar 10 hingga 20 persen dan 20 hingga 30 persen. Hasil ini menunjukan penurunan risiko PJK dengan beraktivitas fisik lebih besar pada laki -laki dibandingkan perempuan (Mora et al., 2007) . Berdasarkan faktor risiko lainnya, terdapat perbedaan risiko PJK pada laki -laki dan perempuan. Laki -laki lebih berisiko terkena PJK karena usia lanjut dan penyakit penyerta (Huxley et al., 2006) . Sedangkan perempuan lebih berisiko terkena PJK akibat faktor gaya hidup seperti perilaku merokok (Huxley \& Woodward, 2011).

\section{Hubungan Usia dengan kejadian penyakit jantung}

Hasil uji Chi-Square menunjukkan bahwa nilai $\mathrm{p}=$ nilai $\mathrm{p}=0.010<0,05 \mathrm{yang}$ artinya ada hubungan yang signifikan antara Usia dengan kejadian Jantung

Usia merupakan faktor risiko penting pada kejadian PJK. Hal ini disebabkan perkembangan PJK dapat dimulai saat individu masih muda dan memerlukan waktu hingga puluhan tahun sebelum munculnya gejala akut PJK (WHO, 2012). Berdasarkan data CDC pada tahun 2010 rate kejadian dan kematian akibat PJK di Indonesia mulai meningkat pada kelompok individu 13 berusia 15 - 20 tahun dan terus meningkat hingga kelompok usia 80 tahun (CDC, 2013). Usia munculnya gejala PJK bergantung pada faktor risiko yang dimiliki pada individu dan pada umumnya gejala PJK dialami oleh individu berusia 
lanjut. Hasil penelitian oleh Jones (2006) menunjukan bahwa usia lanjut atau berusia > 50 tahun meningkatkan risiko PJK pada laki laki sebesar 51,7\% (95\% CI 49,3\% - 54,2\%) dan pada perempuan $39,2 \%$ (95\% CI $37 \%$ $41,4 \%)$. Individu yang tidak memiliki faktor risiko terhadap PJK selama 50 tahun pada masa hidupnya memiliki risiko yang sangat rendah terkena PJK (Lloyd-Jones et al., 2006)

\section{Hubungan Kebiasaan merokok dengan kejadian penyakit jantung}

Hasil uji Chi-Square menunjukkan bahwa nilai $\mathrm{p}=0,001<0,05$ yang artinya ada hubungan yang signifikan antara Merokok dengan kejadian Jantung.

Perilaku merokok merupakan faktor risiko yang dapat dihindari dan salah satu faktor yang berkontribusi terhadap kejadian PJK. Merokok merupakan penyebab dari $10 \%$ kasus PJK (WHO, 2011) . Dampak merokok terhadap penderita PJK salah satunya penurunan angka harapan hidup dibandingkan individu yang tidak merokok (Huxley \& Woodward, 2011). Individu yang merokok berisiko terkena PJK 25\% lebih tinggi dibandingkan yang tidak merokok sama sekali (RR 1,25\% 95\% CI 1,12 - 1,39, p<0001) (Huxley \& Woodward, 2011). Pada penelitian lainnya menunjukan peningkatan risiko lebih besar terhadap kejadian PJK. Penelitian oleh Glynn (2005), individu yang merokok memiliki risiko $84 \%$ lebih tinggi 14 terkena PJK (RR 1,84 95\% CI 1,57 - 2,17) dan individu yang sudah berhenti merokok lebih berisiko mengalami PJK sebesar 12\% (RR $1,1295 \%$ CI 1,00-1,27) dibandingkan yang tidak pernah merokok sama sekali. Meskipun demikian peneliti juga menyatakan bahwa lama merokok juga mempengaruhi risiko PJK akibat merokok (Glynn \& Rosner, 2005).

\section{Hubungan Hipertensi dengan kejadian penyakit jantung}

Hasil uji Chi-Square menunjukkan bahwa nilai $\mathrm{p}=0,000<0,05$ yang artinya ada hubungan yang signifikan antara Hipertensi dengan kejadian Jantung.

IMT merupakan salah satu karakteristik individu yang penting dalam kejadian PJK.Berdasarkan penelitian sebelumnya, risiko PJK ditemukan lebih besar pada individu dengan IMT kurang dan lebih atau gemuk serta pada individu yang mengalami obesitas. Penelitian oleh Suastika, dkk (2011) menunjukan bahwa individu dengan IMT kurang berisiko 3,59 kali terkena PJK (OR 3.59 95\%CI 1.48-8.68) (Suastika, et al., 2011). Selain itu, risiko PJK juga ditemukan pada setiap pertambahan IMT. Berdasarkan hasil penelitian oleh Labounty, dkk (2013) menunjukan kenaikan IMT sebesar $5 \mathrm{~kg} / \mathrm{m} 2$ akan meningkatkan risiko PJK sebesar 1,25 kali (OR 1.25 95\%CI 1.20-1.30). Hasil ini menunjukan bahwa pertambahan berat badan akan meningkatkan risiko kesakitan dan kematian akibat PJK karena terjadi peningkatan keparahan PJK sesuai dengan pertambahan IMT (Labounty, et al., 2013). Selain IMT kurang dan lebih, obesitas merupakan faktor penting dalam kesakitan ataupun kematian akibat PJK. Obesitas mempengaruhi perkembangan PJK secara langsung maupun tidak langsung. Obesitas berdampak pada faktor metabolism tubuh seperti peningkatan tekanan darah, peningkatan kadar kolesterol dan resistensi insulin yang merupakan faktor risiko dari PJK (WHO, 2011; Villareal et al., 2006) . Berdasarkan hasil penelitian, obesitas memiliki hubungan positif terhadap peningkatan risiko PJK pada individu yang mengalami Obesitas(RR 3,44 95\% CI 2,814,21) (Li et al., 2006). Hal ini sesuai dengan penelitian oleh Jones, (2006) yang menemukan bahwa Obesitas meningkatkan risiko PJK pada laki-laki dan perempuan sebesar $41 \%$ dan 21\%. Peningkatan risiko PJK akibat Obesitas lebih tinggi pada perempuan dibandingkan pada laki-laki (Lloyd-Jones et al.,2006).

\section{Hubungan Diabetes (DM) dengan kejadian penyakit jantung}

Hasil uji Chi-Square menunjukkan bahwa nilai $\mathrm{p}=0,000<0,05$ yang artinya ada hubungan yang signifikan antara Diabetes dengan kejadian Jantung.

Hasil penelitian di atas sejalan dengan nhasil penelitian Yuliani(2015) mengenai Hubungan Berbagai Faktor Risiko Terhadap Kejadian Penyakit Jantung Koroner Pada Penderita Diabetes Melitus Tipe 2 dimana hasil Penelitian menunjukkan bahwa faktor risiko yang berhubungan dengan kejadian PJK pada penderita DM tipe 2 adalah jenis kelamin $(\mathrm{p}=0,000)$, lama menderita $\mathrm{DM} \quad(\mathrm{p}=0,043)$, hipertensi $(\mathrm{p}=0,007)$, dislipidemia $(\mathrm{p}=0,000)$, obesitas $(\mathrm{p}=0,023)$, dan merokok $(\mathrm{p}=0,000)$. 
Kesimpulan: Terdapat hubungan yang sangat bermakna $(p<0,0001)$ antara jenis kelamin, dislipidemia, dan merokok dengan kejadian PJK pada penderita DM tipe 2 dan terdapat hubungan yang bermakna $(\mathrm{p}<0,05)$ antara lama menderita DM, hipertensi, obesitas dengan kejadian PJK pada penderita DM tipe 2.

\section{Hubungan Obesitas dengan kejadian penyakit jantung}

Hasil uji Chi-Square menunjukkan bahwa nilai $\mathrm{p}=0,000<0,05$ yang artinya ada hubungan yang signifikan antara Diabetesdengan kejadian Jantungtidak mengalami kejadian jantung

Hasil penelitian di atas sejalan dengan hasiol peneltian Andinisari (2012) mengenai Hubungan Obesitas Sentral Dengan Penyakit Jantung Koroner Di Puskesmas Kota Bogor dimana Hasil Prevalensi obesitas sentral sebesar $65 \%$ atau 130 orang, 30 orang laki-laki dengan obesitas sentral $(42,3 \%)$ dan 100 perempuan dengan obesitas sentral $(77,5 \%)$. Prevalensi penderita PJK sebanyak 36 orang atau $18 \%$. Penderita PJK yang mengalami obesitas sentral sebanyak 24 orang (12\%).Analisis bivariat dengan chi-square didapatkan bahwa obesitas sentral bukan merupakan faktor risiko terjadinya penyakit jantung koroner (RP 1,077; 95\% CI 0,5742,$020 ; p$ 0,817) dan hal ini tidak bermakna secara statistik. Variabel bebas yang bermakna secara statistik adalah variabel usia (RP 2,097; 95\% CI 1,127-3,900; p 0,025), usia tua ( $\geq 60$ tahun) lebih berisiko 2 kali untuk mendapatkan PJK dibandingan dengan usia 18-59 tahun. Hipertensi meningkatkan risiko PJK 2,4 kali (RP 2,381; 95\% CI 1,099-5,161) dibandingkan dengan bukan penderita hipertensi. Hasil analisis multivariat dengan regresi logistik menunjukan bahwa tidak ada satupun variabel bebas yang mempunyai hubungan bermakna secara statistik dengan PJK.Usia setelah mempertimbangkan obesitas sentral dan hipertensi meningkatkan risiko 2 kali (RP 2,095; 95\% CI 0,861-5,094; p 0,103) namun tidak bermakna secara statistik. Hipertensi berisiko 2,4 kali untuk menjadi PJK setelah mempertimbangkan usia dan obesitas sentral (RP 2,402; 95\% CI 0,970-5,946; p 0,058), namun tidak bermakna secara statistik. Obesitas sentral karena merupakan substansi penting dalam penelitian ini maka diikut sertakan dalam perhitungan multivariat, hasilnya tetap tidak terdapat hubungan yang bermakna secara statistik dengan PJK setelah mempertimbangkan usia dan hipertensi (RP 1,$102 ; 95 \%$ CI 0,505-2,408, p 0,808).

\section{Hubungan aktifitas fisik dengan kejadian penyakit jantung}

Hasil uji Chi-Square menunjukkan bahwa nilai $\mathrm{p}=0,000<0,05$ yang artinya ada hubungan yang signifikan antara aktifitas fisikdengan kejadian Jantungtidak mengalami kejadian jantung

Hasil penelitian Alfajar (2013) mengenai Hubungan aktivitas fisik dan kejadian penyakit jantung koroner di Indonesia: analisis data Riskesdas tahun 2013 Hasil analisis ini menunjukan individu yang rutin beraktivitas fisik cenderung memiliki risiko yang lebih rendah terhadap PJK meskipun memiliki faktor risiko PJK lainnya.

\section{KESIMPULAN DAN SARAN \\ Kesimpulan}

Berdasarkan hasil penelitian dapat disimpulkan bahwa :

1. Jenis kelamin berpengaruh terhadap kejadian jantung koroner

2. Usia berpengaruh terhadap kejadian jantung koroner.

3. Kebiasaan Merokok berpengaruh terhadap kejadian jantung koroner.

4. Hipertensi berpengaruh terhadap kejadian jantung koroner.

5. Diabetes (DM) berpengaruh terhadap kejadian jantung koroner.

6. Obesitas berpengaruh terhadap kejadian jantung koroner.

7. Aktifitas fsik berpengaruh terhadap kejadian jantung koroner.

\section{Saran}

Mengingat hasil penelitian ini disampaikan saran-saran sebagai berikut :

1. Agar RSUD Pirngadi Medan tidak hanya mengutamakan upaya kuratif saja tetapi juga harus mengutamakan upaya promotif dan preventif.

2. Agar mahasiswa Universitas Sari Mutiara Medan dapat menjadikan ini sebagai sumber referensi dan kepustakaan serta dapat mengembangkan penelitian menjadi lebih sempurna.

3. Agar masyarakat lebih waspada dengan Penyakit Jantung Koroner dengan 
melakukan pencegahan mulai dari usia remaja, terutama laki-laki sehingga faktor resiko bisa dikendalikan sejak dini, khususnya pola makan serta menerapkan gaya hidup yang sehat.

4. Agar para peneliti selanjutnya melakukan kajian lebih lanjut tentang Faktor-Faktor Yang Mempengaruhi Terhadap Terjadinya Penyakit Jantung Koroner.

\section{DAFTAR PUSTAKA}

Abidin, 2014. Faktor Risiko Penyakit Jantung Koroner pada Pasien Rawat Inap di Cardiovascular Care Unit (CVCU) Cardiac Centre RSUP Dr.WahidinSudirohusodo Makassar PeriodeJanuari _ $\quad$ Juli 2008.UniveritasHasanuddin.

Afriyanti, 2015. Hubungan antara perilaku merokok dengan Kejadian penyakit jantung coroner. Universitas Sam Ratulangi Manado

Andinisari, 2012. Hubungan Obesitas Sentral Dengan Penyakit Jantung Koroner Di Puskesmas Kota Bogor. Tesis. UGM

Afriyanti, 2015. Hubungan Antara Perilaku Merokok Dengan Kejadian Penyakit Jantung Koroner. Universitas Sam Ratulangi Manado.Jurnal e-Clinic (eCl), Volume 3, Nomor 1, Januari-April 2015

Alkhusari, 2012. Faktor-Faktor Yang Berhubungan Dengan Kejadian Penyakit Jantung Koroner Di Poliklinik Rumah Sakit Muhammadiah Palembang tahun 2013. Vol 8. No. 3 . Desember 2012. Jurnal Kesehatan Bina Husada Sekolah Tinggi Ilmu Kesehatan Bina Husada

Bororing, 2014. Gambaran Kebiasaan Makan Makanan Beresiko Penyakit Jantung Koroner Pada Masyarakat Etnis Minahasa di Lingkungan 2 Kelurahan Bahu Kecamatan Malalayang Kota Manado

Desrini, 2014.Asupan Natrium dan Tekanan Darah sebagai Faktor Risiko Peningkatan Kadar C-Reactive Protein (Crp) pada Remaja Obesitas dengan Sindrom Metabolik. Program Studi Ilmu Gizi Fakultas Kedokteran Universitas Diponegoro. Journal of Nutrition College, Volume 3, Nomor 3, Tahun 2014

Diastutik, 2016. Proporsi Karakteristik Penyakit Jantung Koroner Pada Perokok Aktif Berdasarkan Karakteristik Merokok.
Jurnal Berkala Epidemiologi, Vol. 4 No. 3, September 2016: 326-337

Indrawati, 2014. Hubungan antara pengetahuan, sikap, persepsi, motivasi, Dukungan keluarga dan sumber informasi pasien penyakit jantung koroner dengan tindakan pencegahan sekunder factor risiko (studi kasus di rspad gatot soebroto jakarta). Jurnal Ilmiah WIDYA. Volume 2 Nomor 3 Agustus-Oktober 2014

Santoso, 2013. Hubungan Skor Apgar Keluarga Dan Tingkat Pengetahuan Satpam Universitas Muhammadiyah Yogyakarta Dengan Respon Surat Keputusan Rektor Tentang Kawasan Tanpa Rokok. Universitas Muhammadiyah Yogyakarta.

Setianto, 2013. Efek Perioperatif Statin pada Kematian,Infark Miokard, Fibrilasi Atrial, dan Lama Perawatan (Meta-Analisis). Tabloid Profesi, Kardiovaskuler. 203 /Thn. XI X/Maret 2014

Sari, 2016. Penatalaksanaan Gagal Jantung NYHA II disertai Pleurapneumonia pada Laki - laki Usia 38 Tahun Fakultas Kedokteran, Universitas Lampung

Widiastuti, 2016. Faktor determinan produktivitas kerja pada pekerja wanita. Vol. 4, No. 1, Desember 2015: 2837.Jurnal Gizi Indonesia (ISBN : 18584942)

Yuliani, 2014. Hubungan Berbagai Faktor Risiko Terhadap Kejadian Penyakit Jantung Koroner Pada Penderita Diabetes Melitus Tipe 2. Fakultas Kedokteran Universitas Andalas. Jurnal Kesehatan Andalas. 2014; 3(1) 